\title{
Left Ventricular Mid Anterior Segment
}

National Cancer Institute

\section{Source}

National Cancer Institute. Left Ventricular Mid Anterior Segment. NCI Thesaurus. Code C127661.

The anterior portion of the mid-cavity division of the left ventricular myocardium as determined using the AHA 17-Segment Model (Cerqueira et al., 2002). 